\title{
Editorial
}

\author{
Christopher M.A. Brett and Hugh D. Burrows
}

\section{IUPAC and the Organisation for the Prohibition of Chemical Weapons (OPCW)}

\author{
https://doi.org/10.1515/pac-2020-0110
}

Keywords: Chemical Weapons Convention; IUPAC; Organisation for the Prohibition of Chemical Weapons.

The Chemical Weapons Convention aims to eliminate the production and use of all chemical warfare agents. It is an international treaty, with 193 participating nation states, and entered into force in 1997. It prohibits the development, production, stockpiling or use of chemical weapons. The Organisation for the Prohibition of Chemical Weapons (OPCW) is responsible for the implementation of their elimination within the terms of the Convention [1]. It is based in The Hague (The Netherlands), and has a staff of around 400 people, with the transdisciplinary expertise, necessary for ensuring that the goals of the Chemical Weapons Convention are achieved. The OPCW was awarded the 2013 Nobel Prize for Peace "For its extensive efforts to eliminate chemical weapons".

The International Union of Pure and Applied Chemistry (IUPAC) shares many of the goals of the OPCW, and the two organizations have collaborated extensively through workshops, articles and special issues in the IUPAC publications Pure and Applied Chemistry and Chemistry International, sharing of scientific and technical expertise, and organization of educational and outreach activities.

In November 2019, IUPAC received the 2019 OPCW-The Hague Award for Outstanding Contributions to a World Free of Chemical Weapons, jointly with Dr Robert Mikulak, the former Permanent Representative of the United States to the OPCW, and Mr Cheng Tang, expert on chemical demilitarisation from the People's Republic of China [2]. This highly prestigious award represents recognition of IUPAC's "strong and lasting cooperation with OPCW to serve humankind through contributing knowledge and advances in the science and technology of chemistry at the worldwide level, helping to achieve the goals of CWC, as well as providing OPCW with the tools and materials for informing society about the responsible uses of chemistry."

Pure and Applied Chemistry is happy to celebrate the OPCW-The Hague Award for Outstanding Contributions to a World Free of Chemical Weapons through a virtual issue of the Journal, containing articles associated with the collaboration with OPCW from IUPAC publications.

\section{References}

[1] J. E. Forman, C. M. Timperley, S. Sun, D. van Eerten, Pure Appl. Chem. 90, 1507 (2018).

[2] https://www.opcw.org/media-centre/news/2019/11/three-winners-receive-2019-opcw-hague-award-outstanding-contributions, cited 21st January 2020.

Corresponding authors: Christopher M.A. Brett, President, International Union of Pure and Applied Chemistry, Department of Chemistry, University of Coimbra, 3004-535 Coimbra, Portugal, e-mail: cbrett@iupac.org; and Hugh D. Burrows, Scientific Editor, Pure and Applied Chemistry, Department of Chemistry, University of Coimbra, 3004-535 Coimbra, Portugal, e-mail: burrows@ci.uc.pt 